\title{
Hypercalcemia in Colorectal Cancer
}

\author{
By Rakin Jamal BSc and Caroline Mariano MD, FRCPC
}

Rakin Jamal is a second-year medical student at the University of British Columbia. Caroline Mariano is a medical oncologist at Royal Columbian Hospital and is with the Department of Medicine at the University of British Columbia.

Submitted: April 19, 2017. Accepted June 15, 2017. Published December 29, 2017.

\begin{abstract}
Humoral hypercalcemia of malignancy is common in many cancers but is rarely present in colorectal cancers with only 24 documented cases in the literature. In this report, we present a case of a 67-year-old woman complaining of right sided abdominal pain and diarrhea. Imaging showed an obstructing cecal mass and the pathological diagnosis was poorly differentiated adenocarcinoma. After a hemicolectomy, she developed humoral hypercalcemia of malignancy which was treated with intravenous bisphosphonates. She continued to worsen due to her rapid progression of disease and died less than one month after her initial diagnosis. We reviewed the 24 other documented cases to investigate the prognosis of hypercalcemia in colorectal cancers along with reviewing the clinical presentation and management of humoral hypercalcemia of malignancy.
\end{abstract}

\section{Résumé}

L'hypercalcémie humorale maligne est courante dans de nombreux cas de cancers, mais elle est rare dans les cancers colorectaux; la documentation recense 24 cas seulement. Dans le présent article, nous décrivons le cas d'une femme de 67 ans se plaignant de douleurs abdominales du côté droit et de diarrhée. Un examen d'imagerie indiqua la présence d'une masse caecale obstructive dont le diagnostic pathologique sest avéré être celui d’un adénocarcinome peu différencié. À la suite d'une hémicolectomie, la patiente a développé une hypercalcémie humorale maligne qui a été traitée à l'aide de bisphosphonates intraveineux. Son état a continué de se détériorer en raison de la progression rapide de la maladie et la patiente est décédée moins d'un mois après le diagnostic initial. Nous passons en revue les 24 cas documentés pour analyser les pronostics d'hypercalcémie dans les cas de cancers colorectaux, tout en examinant le tableau clinique et la prise en charge de l'hypercalcémie humorale maligne.

Hypercalcemia is a common metabolic manifestation of cancer, historically affecting $20-30 \%$ of all cancer patients. ${ }^{1}$ The mechanisms of malignancy-related hypercalcemia are ectopic hyperparathyroidism, calcitriol secreting lymphomas, local osteolytic hypercalcemia and humoral hypercalcemia of malignancy (HHM). ${ }^{2}$ The two most common causes of hypercalcemia in malignancy are local osteolytic hypercalcemia and HHM, with HHM being the most common. The underlying mechanism of the hypercalcemia is increased osteolytic activity which can be achieved with or without bone metastasis. ${ }^{3}$ In local osteolytic hypercalcemia, bone metastasis causes local destruction and increased osteolytic activity. In humoral hypercalcemia of malignancy (HHM), tumours secrete increased levels of a parathyroid hormone related protein (PTHrP) which mimics parathyroid hormone systemically. This results in an increased level of both bone resorption and renal retention of calcium. Cancers associated with HHM include breast cancer, renal cancer, ovarian cancer, endometrial cancer, and lymphoma along with squamous cell cancers of the head and neck, esophagus, lung, and cervix. ${ }^{2}$ HHM associated with colorectal cancers are rare with only 24 documented cases in the literature. In addition to reviewing the literature to characterize the prognosis, we report another case of colorectal cancer with HHM. 


\section{Case Description}

A 67-year-old woman presented to the emergency room with right sided abdominal pain and diarrhea. She had been well up until 2 weeks prior with no obstructive symptoms, bleeding or weight loss. She had no past medical history, and took no medications. She had no family history of cancer. She was an ex-smoker who drank alcohol minimally. Computed tomography (CT) scan of her abdomen revealed a large cecal mass and multiple lesions in her liver concerning for metastases. A colonoscopy was performed where a mass was seen in the ascending colon. A biopsy showed poorly differentiated non-small cell carcinoma compatible with high grade primary colonic adenocarcinoma. The tumour demonstrated loss of CDX2 and CD20, which is associated with a negative prognosis. ${ }^{4}$ A screen for mismatch repair proteins was negative. The patient was discharged home with plans for outpatient management. 28 days later she developed abdominal pain and returned to hospital and was found to have a large bowel perforation on a subsequent CT scan. The previously noted liver lesions had grown in size and number. Her vitals were stable and she was afebrile. Physical exam revealed tenderness to deep palpation in the right upper and lower quadrant with no rebound tenderness or guarding. Laboratory investigations showed elevated liver enzymes and hypoalbuminemia $(29 \mathrm{~g} / \mathrm{L}$, normal $>35 \mathrm{~g} / \mathrm{L})$. She was stabilized and placed on broad spectrum antibiotics in preparation for a laparoscopic right hemicolectomy which was performed later that week.

Seven days post-operatively she developed delirium and the internal medicine service was consulted. The workup of her delirium involved a CT head, which was negative and she remained on intravenous antibiotics (piperacillin-tazobactam). Her blood and urine cultures showed no growth. Her medications were also reviewed and no offending medications could have caused her delirium outside of narcotic analgesia. Serum calcium was checked and was elevated $(2.95 \mathrm{mmol} / \mathrm{L}$, normal $<2.60$ $\mathrm{mmol} / \mathrm{L})$. Her laboratory data also showed hypophosphatemia $(0.6 \mathrm{mmol} / \mathrm{L}$, normal $>0.8 \mathrm{mmol} / \mathrm{L})$, a severe deficiency in 25 hydroxyvitamin $\mathrm{D}(19 \mathrm{nmol} / \mathrm{L}$, moderate deficiency $>25 \mathrm{nmol} / \mathrm{L})$, and a supressed parathyroid hormone $(\mathrm{PTH})(0.5 \mathrm{pmol} / \mathrm{L}$, normal $>1.5 \mathrm{pmol} / \mathrm{L})$. Renal function was normal. Subsequent testing revealed very high levels of PTH related peptide (PTHrP) (36 $\mathrm{pg} / \mathrm{mL}$, high $<30 \mathrm{pg} / \mathrm{mL}$ ). A bone scan was negative for bony metastases. She was treated with IV pamidronate and 2 days later her calcium normalized. She continued to deteriorate and her liver enzymes increased while her hypoalbuminemia worsened. Treatment began to focus on supportive palliative measures and she died 13 days from her diagnosis of hypercalcemia and 27 days from her diagnosis of colon cancer.

\section{Discussion}

\section{Clinical Presentation}

The most common symptom of malignancy-associated hypercalcemia is fatigue followed by confusion, anorexia, pain, polydipsia/polyuria, constipation and nausea. ${ }^{5} \mathrm{~A}$ rapid increase in calcium levels along with higher levels of calcium are associated with neurological symptoms such as confusion which was seen in our patient. ${ }^{5}$ If these symptoms are present in patients with colorectal cancers, hypercalcemia should be considered despite its rare occurrence. Investigations into serum calcium levels should be accompanied by levels of ionized calcium since abnormal albumin levels can cause misinterpretation of results. ${ }^{2}$ Once hypercalcemia is diagnosed, it is important to investigate the mechanism and consider concomitant primary hyperparathyroidism along with other non-malignant mechanisms. The diagnosis of HHM can be confirmed with elevated PTHrP measurements but can also be made on clinical grounds. ${ }^{2}$

\section{Management}

IV bisphosphonates such as pamidronate and zoledronic acid have been well documented to effectively treat malignancyassociated hypercalcemia by blocking the PTHrP mediated osteoclastic bone resorption. ${ }^{2,6,5}$ Calcitonin can be used in the acute setting to rapidly decrease calcium levels, although its use is limited by tachyphylaxis which typically occurs within 48 hours. Intravenous hydration can alleviate associated dehydration and renal dysfunction. IV bisphosphonates are very efficacious with $60-90 \%$ of patients having normalized calcium levels within 4-7 days that lasts up to 3 weeks. ${ }^{2,7}$ Zoledronic acid reduces calcium levels faster than pamidronate and is more effective in patients with moderate to severe hypercalcemia. ${ }^{8}$ Bisphosphonates such as zoledronic acid are generally well tolerated but can cause elevations in serum creatinine. Serum creatinine should be monitored before each dose and extra caution should be applied in patients with low creatinine clearance or if other nephrotoxic medications are administered. ${ }^{9}$

Management of the underlying malignancy including surgery and/or systemic therapy which can be effective in the long term control of hypercalcemia. ${ }^{10}$ However, patients are often too unwell to receive disease directed therapy, as was the patient in our case.

\section{Prognosis}

Malignancy-associated hypercalcemia has a poor prognosis with primary research reporting median survivals ranging from 30 to 90 days. ${ }^{2,5,6}$ It has been suggested that this poor prognosis is due to hypercalcemia being a marker of advanced disease rather than the hypercalcemia directly causing death. This is supported by research showing that the control of hypercalcemia does not influence survival and that the majority of deaths in cases of 
malignancy-associated hypercalcemia were due to progressive cancer and its complications. ${ }^{5,6}$ To compare the prognosis between calcium associated malignancy and HHM in colorectal cancers, we reviewed the 24 published cases (Table 1 ). In the 18 cases that had the prognosis result documented, the median survival after the diagnosis of HHM was 32 days. The similarly poor prognosis is likely due to the same reasons, since colorectal cancers with HHM are associated with poorly differentiated tumours and distant metastasis such as the liver. ${ }^{11}$ This poor prognosis with HHM in colorectal cancer contrasts significantly to the natural history of disease, where median survival in advanced colon cancer is up to 28 months with modern chemotherapy. ${ }^{12}$

\section{Conclusion}

In summary, we present a patient with colorectal cancer associated with HHM that progressed rapidly. While humoral hypercalcemia is rare in colorectal cancers, it is associated with a poor prognosis and should be considered in patients who have symptoms or present with aggressive disease. If appropriate with treatment goals, IV bisphosphonates should be administered to relieve symptoms.

\section{References}

1. Basso U, Maruzzo M, Roma A, et al. Malignant hypercalcemia. Curr Med Chem 2011;18(23):3462-67.

2. Stewart AF. Hypercalcemia associated with cancer. N Engl J Med 2005;352(4):373-79.

3. Clines GA, Guise TA. Hypercalcaemia of malignancy and basic research on mechanisms responsible for osteolytic and osteoblastic metastasis to bone. Endocr Relat Cancer 2005;12:549-83

4. Kim, Rhee, Bae JM et al. Loss of CDX2/CK20 expression is associated with poorly differentiated carcinoma, the $\mathrm{CpG}$ island methylator phenotype, and adverse prognosis in microsatellite-unstable colorectal cancer. Am J Surg Pathol 2013 37(10):1532-4

5. Ralston SH, Gallacher SJ, Patel U, et al. Cancer-associated hypercalcemia: morbidity and mortality. Clinical experience in 126 treated patients. Ann Intern Med 1990;112(7):499-504.

6. Penel N, Dewas S, Doutrelant P, et al. Cancer-associated hypercalcemia treated with intravenous diphosphonates: a survival and prognostic factor analysis Support Care Cancer 2008;16(4):387-92.

7. Fleisch H. Bisphosphonates: mechanisms of action. Endocr Rev 1998;19:80-100.

8. Major P, Lortholary A, Hon J, et al. Zoledronic acid is superior to pamidronate in the treatment of hypercalcemia of malignancy: a pooled

Table 1. Prognosis of Documented Cases of Colorectal Cancers with Humoral Hypercalcemia of Malignancy

\begin{tabular}{|c|c|c|c|}
\hline First author & Year & Primary site & Result after hypercalcemia diagnosis \\
\hline Castleman $^{13}$ & 1963 & Colon & Died after 3 weeks \\
\hline Mozaffarian $^{14}$ & 1969 & Colon & Died after 3 weeks \\
\hline Omenn $^{15}$ & 1969 & Colon & Died with date unreported \\
\hline Kubota $^{16}$ & 1980 & Colon & Died in under 1 month \\
\hline Kubota $^{16}$ & 1980 & Rectum & Died after 1 week \\
\hline Palvio $^{17}$ & 1985 & Rectum & Died after 2 months \\
\hline Chevinsky $^{18}$ & 1987 & Colon & Died after 6 days \\
\hline Berkelhammer $^{19}$ & 1989 & Colon & Died after 2 weeks \\
\hline March $^{20}$ & 1991 & Rectum & Died with date unreported \\
\hline Gurney $^{21}$ & 1993 & Colon & Result not reported \\
\hline Gurney $^{21}$ & 1993 & Colon & Result not reported \\
\hline Links $^{22}$ & 1994 & Colon & Died after 7 months \\
\hline De Souza $^{23}$ & 1995 & Rectum & Died after 3 weeks \\
\hline Sidler $^{24}$ & 1996 & Colon & Died after 6 months \\
\hline Petrelli $^{25}$ & 1996 & Colon & Died with date unreported \\
\hline Sekine $^{26}$ & 1998 & Colon & Result not reported \\
\hline Lortholary $^{27}$ & 1999 & Colon & Died 5 weeks later \\
\hline Lortholary ${ }^{27}$ & 1999 & Rectum & Died 7 weeks later \\
\hline Thompson ${ }^{28}$ & 2001 & Colon & Alive with disease 10 months later \\
\hline Luh $^{29}$ & 2002 & Colon & Died 6 months later \\
\hline Sakata $^{11}$ & 2005 & Colon & Died 3 weeks later \\
\hline Fujita ${ }^{30}$ & 2005 & Colon & Died 4 months later \\
\hline Cooper $^{31}$ & 2006 & Rectum & Alive at discharge, date not recorded \\
\hline Current Case & & Colon & Died after 13 days \\
\hline
\end{tabular}


analysis of two randomized, controlled clinical trials. J Clin Oncol 2001;19(2):558-67

9. Berenson JR. Treatment of hypercalcemia of malignancy with bisphosphonates. Semin Oncol 2002;29(6):12-18

10. Rhee P, Joseph B. Shock, Electrolytes and Fluid. In Townsend CM, Beauchamp RD, Evers M, et al. Sabiston textbook of surgery, $20^{\text {th }}$ edition. Philadelphia, Elsevier; 2016:92.

11. Sakata J, Wakai T, Shirai Y, et al. Humoral hypercalcemia complicating adenocarcinoma of the sigmoid colon: report of a case. Surg Today 2005;35:692-95.

12. Heinemann, von Weikersthal, Decker, et al. FOLFIRI plus cetuximab versus FOLFIRI plus bevacizumab as first-line treatment for patients with metastatic colorectal cancer (FIRE-3): a randomised, open-label, phase 3 trial. Lancet Oncol 2014;15(10):1065-75.

13. Castleman B, Kibbee BU. Case records of the Massachusetts General Hospital: case 63-1963. N Engl J Med 1963:269:801-8.

14. Mozaffarian G. Hypercalcemia associated with malignancies unexplained by bone metastasis. Case reports and review of literature. J Maine Med Assoc 1969;60:205-7.

15. Omenn GS, Roth SI, Baker WH. Hyperparathyroidism associated with malignant tumors of nonparathyroid origin. Cancer 1969;24:1004-12.

16. Kubota H, Koyama Y, Hojo K, et al. Adenosquamous cell carcinoma of the colon with severe hypercalcemia. Report of two cases. Jpn J Clin Oncol 1980;10:311-20.

17. Palvio DH, Sorensen FB, Klove-Mogensen M. Stem cell carcinoma of the colon and rectum. Report of two cases and review of the literature. Dis Colon Rectum 1985;28:440-5.

18. Chevinsky AH, Berelowitz M, Hoover HC. Adenosquamous carcinoma of the colon presenting with hypercalcemia. Cancer 1987;60:1111-6.

19. Berkelhammer CH, Baker AL, Block GE, et al. Humoral hypercalcemia complicating adenosquamous carcinoma of the proximal colon. Dig Dis Sci 1989;34:142-7.
20. March R, Ulin R, Puccio C, et al. Hypercalcemia associated with adenocarcinoma of the rectum. A case report and review of the literature. Anticancer Res 1991;11:2029-30.

21. Gurney H, Grill V, Martin TJ. Parathyroid hormone-related protein and response to pamidronate in tumor-induced hypercalcemia. Lancet 1993;341:1611-3.

22. Links $\mathrm{M}, \mathrm{Ho} \mathrm{H}$, Clingan $\mathrm{P}$, et al. Hypercalcemia in a patient with fatal adenosquamous carcinoma of the colon. Med J Aust 1994;160:286-7.

23. de Souza PL, Friedlander ML. Humoral hypercalcemia associated with adenocarcinoma of the rectum. A case report and review of the literature. Am J Clin Oncol 1995;18:126-9.

24. Sidler B, Alpert L, Henderson JE, et al. Amplification of the parathyroid hormone-related peptide gene in a colonic carcinoma. J Clin Endocrinol Metab 1996;81:2841-7.

25. Petrelli NJ, Valle AA, Weber TK, et al. Adenosquamous carcinoma of the colon and rectum. Dis Colon Rectum 1996;39:1265-8.

26. Sekine M, Takami H. Combination of calcitonin and pamidronate for emergency treatment of malignant hypercalcemia. Oncol Rep 1998;5:197-9.

27. Lortholary AH, Cadeau SD, Bertrand GM, et al. Humoral hypercalcemia in patients with colorectal carcinoma: report of two cases and review of the literature. Cancer 1999;86:2217-21.

28. Thompson JT, Paschold EH, Levine EA. Paraneoplastic hypercalcemia in a patient with adenosquamous cancer of the colon. Am Surg 2001;67:585-8.

29. Luh JY, Han ES, Simmons JR, et al. Poorly differentiated colon carcinoma with neuroendocrine features presenting with hypercalcemia and cutaneous metastases: case report and review of the literature. Am J Clin Oncol 2002;25:160-3.

30. Fujita T, Fukuda K, Nishi H, et al. Paraneoplastic hypercalcemia with adenosquamous carcinoma of the colon. Int J Clin Oncol 2005;10(2):144-7.

31. Cooper WC, Magee CC. Humoral hypercalcemia of malignancy presenting after oncologic surgery. Kidney Int 2006;70(1):225-29.

\title{
Connect Your Worlds!
} medicine career at:

\author{
saskdocs.ca/im
}

\section{saskdocs.ca 1//}

